\title{
Study on the effect of gasket thickness for bolted gearbox flange joint
}

\author{
S. H. Gawande ${ }^{1}$ (D) \\ (c) Springer Nature Switzerland AG 2018
}

\begin{abstract}
A gasket is fitted between two or more mating flanges which fills the gap and acts as mechanical seal; it prevents leakage when flanges are in compression. In order to obtain perfect sealing and joint, proper selection of gasket thickness and gasket material is essential. In the majority of cases, mechanical seal is obtained by gasket when external forces are applied; this allows gasket material to flow into the irregularities between the flange surfaces; external forces can be applied by the bolt under load (bolt preload). The preload should be applied equally over the whole seating area to obtain a complete sealing. Hence, preload plays an important role and performance of gasket joint depends upon preload. In this study, finite element analysis of bolted gearbox flange joint has been carried out and numerical results have been compared by taking experimentally the obtained characteristics of the gaskets for various thicknesses. This study reveals that the gasket thickness plays a vital role in the seal performance of gearbox flange assembly. Hence, it is found that the gasket with $3 \mathrm{~mm}$ thickness showed a significant reduction in the deformation and stresses.
\end{abstract}

Keywords Gasket · Gearbox flange · Deformation · von Mises stresses

\section{Introduction}

Once gasket is being assembled, the gearbox assembly becomes a vital part of the total engine structure. It supports the engine head along with its operational component. This should be capable of sustaining the static forces which are transmitted to the block and head. These types of the engine applications are the determining factors in a gearbox gaskets design. The design and material of the gasket are vital for its functional life period. Traditionally, gaskets are produced from paper, rubber, metal, cork and other materials. There are some disadvantages in traditional gaskets; external load is required to deform the gasket in order to fit into non-uniform surface of a flange. However, over the time period, it starts to lose its elastic properties and becomes less resilient; this leads to compression set in the gaskets. A load on the gasket and relative motion cause a overall decrease in the thickness of the gasket, which results in loosing bolt clamp load and leakage.

When gearbox flange is assembled with gasket, these flange gasket seals or joints are subject to the compressive pressures in between the face of the flange; usually this can be achieved by the bolt under load. To make sure the seal is maintained throughout its lifetime of assembly, adequately high pressures should remain on the surface of a gasket to prevent its leakage.

Guruchannabasavaiah et al. [1] addressed the amount of bolt force required to compress the gasket seal in a pressure vessel under the effect of temperature and pressure. Jagale et al. [2] reviewed the behavior of bolted flange joint, and analysis was carried out. Kaswala et al. [3] discussed bolt preload or pretension. This explanation was provided by a graphical method. Factor of safety is calculated by analysis method. Omiya et al. [4] analyzed the gasket stress distributions, stress in the hub and a variation in axial bolt force in bolted gasketed pipe flange connections

S. H. Gawande, shgawande@gmail.com | 'Department of Mechanical Engineering, M.E.S. College of Engineering, S.P. Pune University, Pune, India. 
under internal pressure. Kapgate et al. [5] analyzed deformation, contact pressures, slippage during preload and failure stresses as bolted joints are subjected to preload, shear and bending loads. Lee et al. [6] found that sealing efficiency of gasket depends on the prestressing force of the hold-down bolts, without the thermal stresses. Kumar et al. [7] investigated the structural analysis of a cylinder head under different loading conditions with the numerical simulation of finite element analysis. Raub et al. [8] presented an overview of the assembly process and model building for creating cylinder head gasket joint. Kumar et al. [9] investigated the stresses induced in the bolts of the flange joint of the pressure vessel due to nonfailure during proof pressure test. Celik [10] studied computer-aided engineering (CAE) methodology. CAE methodology is applied as a method of the solution. The stress distribution is identified on the preloaded/pretension bolt connections using advanced CAE applications. Nelson et al. [11] carried out a three-dimensional finite element analysis to find out the influence of gasket contact stress and sealing performance of the joint on a gasket joint with single and twin gaskets having nonlinear material properties. Mathan et al. [12] investigated the variation in bolt axial force of joints under bending load predicted by the finite element analysis, which compared well with the experimental results. The contact stress distribution obtained from the study showed significant variation in the pattern from the previous material models. Păunescu [13] studied the behavior of gaskets which were used for sealing flanged joints of the pressure vessels and pipes working in variable pressure conditions. Cheng et al. [14] investigated time dependence of flange rotation, the gaskets deformation and the gasket contact stress. Furthermore, the influencing factors of leakage rate were analyzed in detail.

According to the literature and modern industrial survey, it is seen that gasket is a standout among the most vital components in the gearbox flange joint [15]. Gaskets start failing when high compressive forces are set within the joints due to critical load. Over the time of use, gasket gets deformed and this results in the leakage and gasket loses its strength. Hence, gasket deformation plays a vital role in sealing performance. In this study, a detailed analysis is carried out to investigate the effect of the gasket thickness on deformation and von Mises stresses.

\section{Numerical analysis}

\subsection{Finite element analysis procedure}

In this procedure, the study of gasket of gearbox flange of Mahindra Jio mini-truck was carried out. CATIA V5

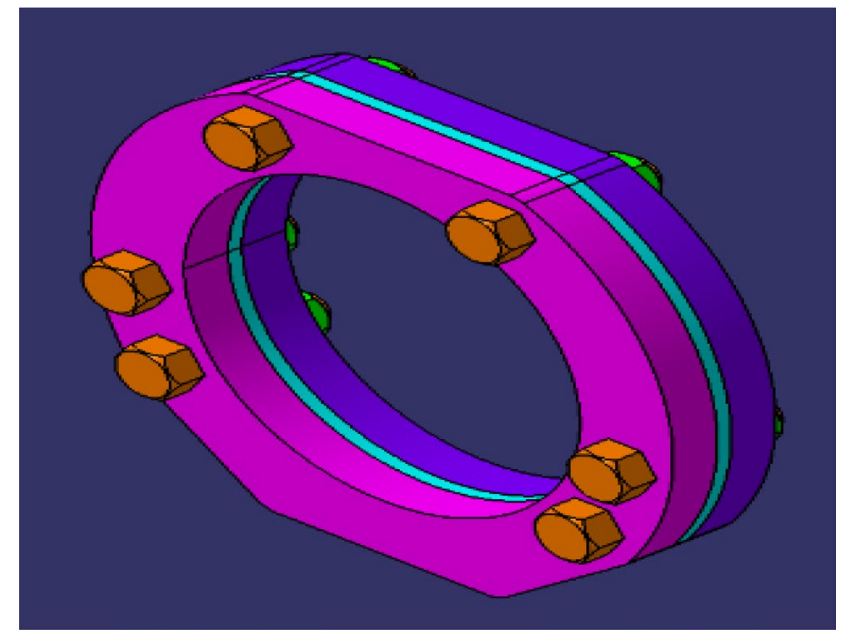

Fig. 1 Model Assembly

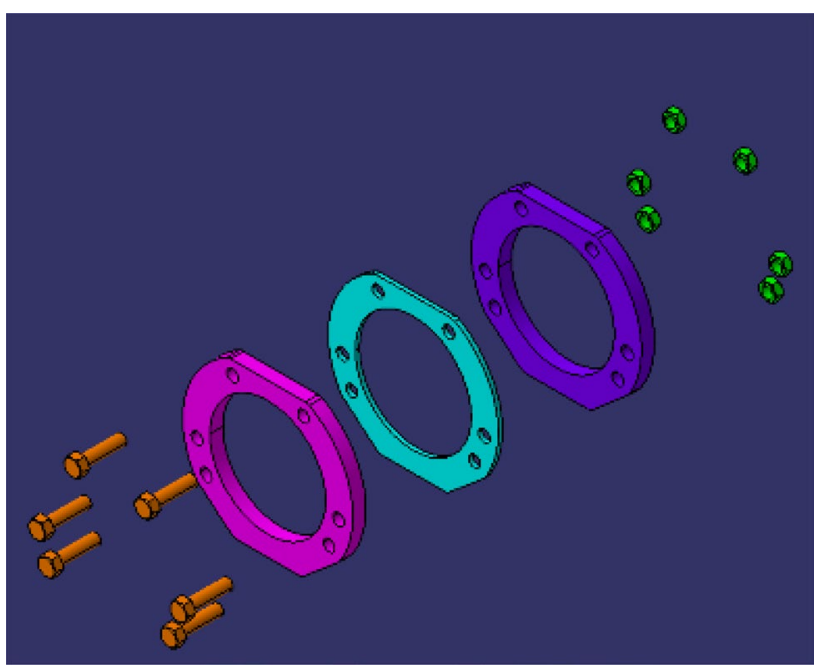

Fig. 2 Exploded view of model

software is used for modeling the assembly of gearbox flange. Existing gearbox gasket dimensions are measured, and gasket CAD model is created using CATIA V5. As shown in Figs. 1 and 2. Gearbox flange model is now converted into IGS format and imported in ANSYS 15 software. Gearbox flange assembly analysis is carried out in three steps.

Step 1 Preprocessing: element property definition, geometric clean up, modeling and meshing.

Step 2 Solution: applying the boundary conditions and loads on the gearbox flangelassembly model and run the solution.

Step 3 Post-processing: results analysis and plotting various parameters such as deformation and stress. 
Table 1 Details of meshing

\begin{tabular}{lllc}
\hline Element type & Number of nodes & $\begin{array}{l}\text { Number of ele- } \\
\text { ments }\end{array}$ & Element size \\
\hline Shell 63 & 11,729 & 1531 & $2 \mathrm{~mm}$ \\
\hline
\end{tabular}

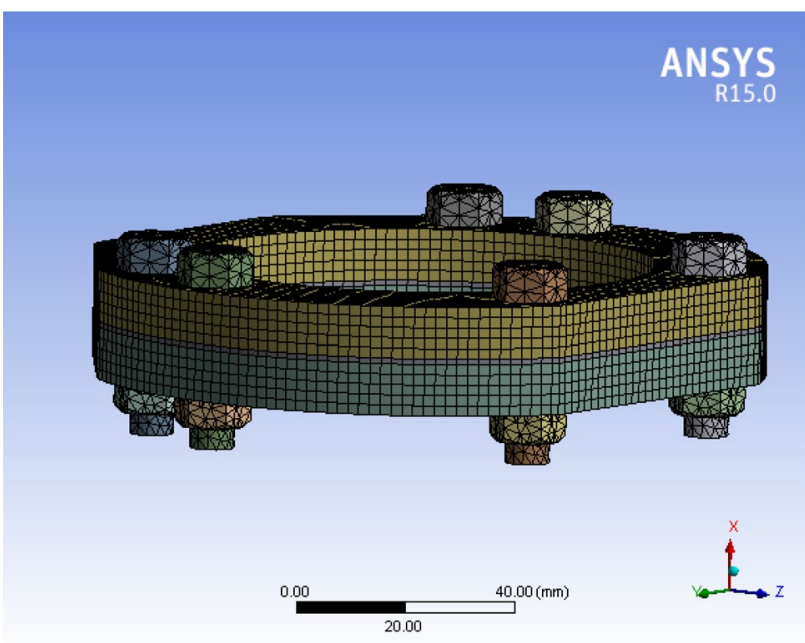

Fig. 3 Meshed model of gearbox flange assembly

\subsection{Meshing and element type}

After the preparation of the model, the gearbox flange assembly is meshed along with the nodes and elements and the attributes of elements are set. This help to prepare the finite element mesh with the ANSYS software. Defining the elements attributes is the vital step as it decides the computational time and accuracy of analysis. Element type SHELL63 is shown in Table 1. These elements represent thin solids like sheet metals (thickness is very small compared to overall dimensions); gasket is meshed with 2D SHELL63 element; the number of nodes is 4 .

At the mid-surface of the solid, shell elements are generated. Figures 3 and 4 show the meshed model of gearbox flange and gasket. As it is essential to conduct analysis, a contact is created between gearbox flange-gasket and gasket-engine flange,

Table 1 indicates details of meshing, and Table 2 indicates material properties used for gearbox gasket-sealant flange assembly.

\subsection{Loading and boundary conditions}

The meshed model and boundary conditions are applied to the system as shown in Fig. 5. The assembly of gasket along with gearbox side flange and engine block side

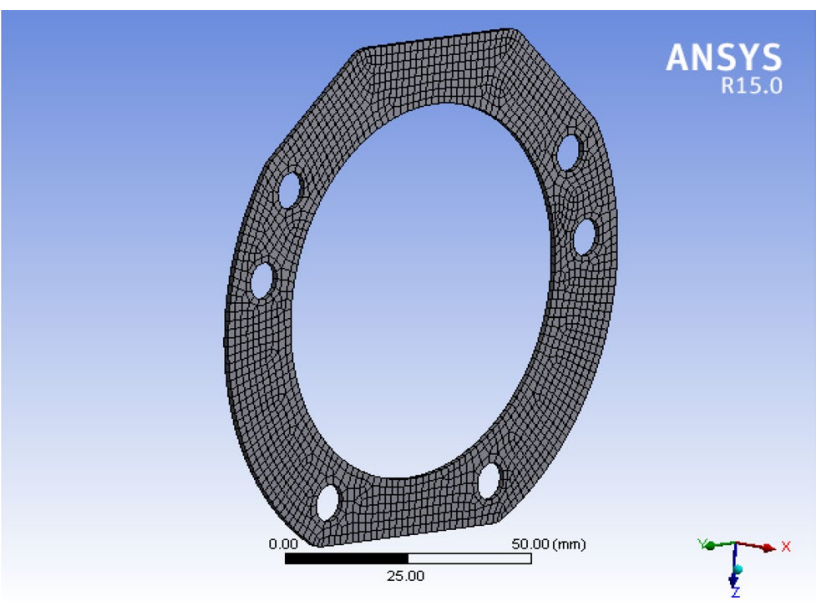

Fig. 4 Meshed model of gasket

Table 2 Details of material properties for Fe analysis

\begin{tabular}{lll}
\hline Material & Structural steel & Traditional gasket \\
\hline Young's modulus (MPa) & $2.1 \times 10^{5}$ & Multi-elastic \\
Poisson's ratio & 0.30 & 0.29 \\
\hline
\end{tabular}

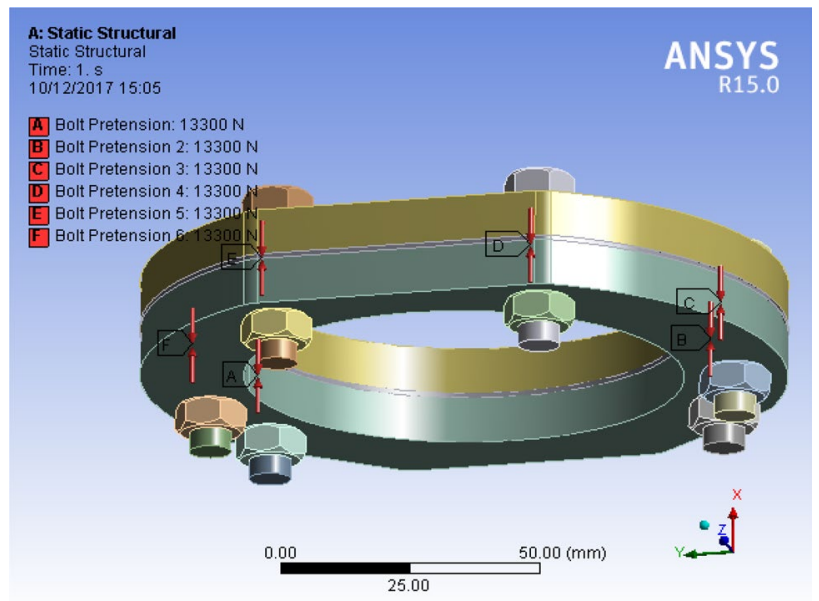

Fig. 5 Loading and boundary condition

flange is coupled with the help of six M8 nut and bolts. Figure 6 FEA shows the properties of gasket flange.

\section{Experimental work}

Gearbox side flange and engine side flange were manufactured as per the dimensions specific to the Mahindra Jio mini-truck assembly. Accordingly, surface preparation was done on gearbox side flange and engine side flange. 


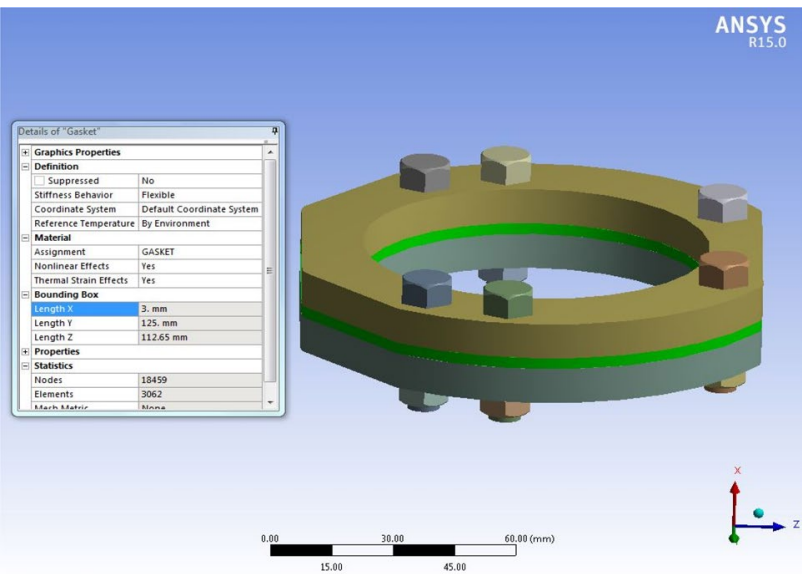

Fig. 6 FEA properties for gasket flange

Table 3 STS-248 machine specification

\begin{tabular}{llll}
\hline Load capacity & $\begin{array}{l}\text { Cross head speed } \\
\text { (Min) }\end{array}$ & $\begin{array}{l}\text { Cross head speed } \\
\text { (Max) }\end{array}$ & $\begin{array}{l}\text { Test speed } \\
\text { accuracy }\end{array}$ \\
\hline $10,000 \mathrm{~N}$ & $3 \mathrm{~mm} / \mathrm{min}$ & $500 \mathrm{~mm} / \mathrm{min}$ & $0.1 \mathrm{~mm}$ \\
\hline
\end{tabular}

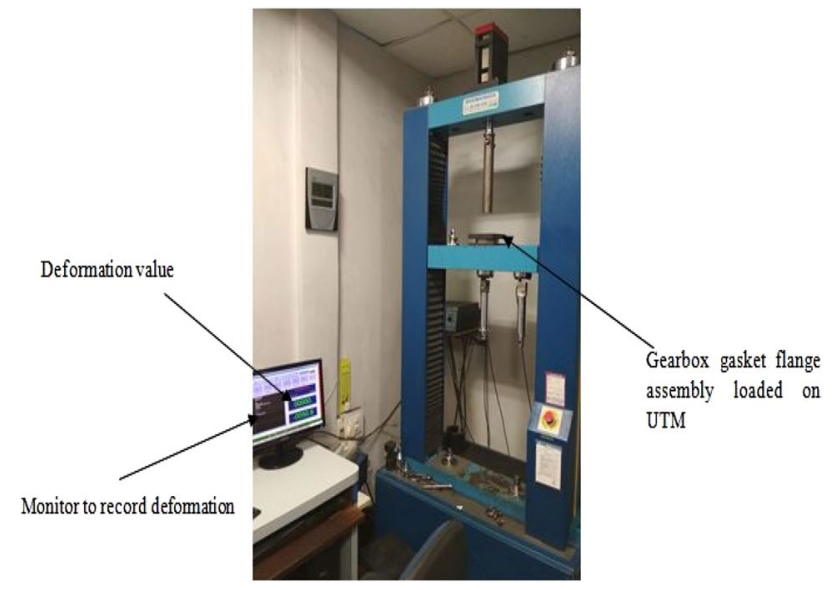

Fig. 7 STS-248 UTM

Preload tension which is a deciding factor for the deformation of gasket acts as a compressive force for gasket. Hence, we conducted compression test, on Universal Testing machine STS-248. Machine specifications are given in Table 3. The experimental work was performed at Praj Metallurgical Laboratory, Pune (Fig. 7).

\subsection{Bolted gearbox flange joint for $1 \mathrm{~mm}, 2 \mathrm{~mm}$ and $3 \mathbf{~ m m}$ thicknesses}

In between the gearbox side flange and engine side flange, gaskets with different thicknesses are placed.

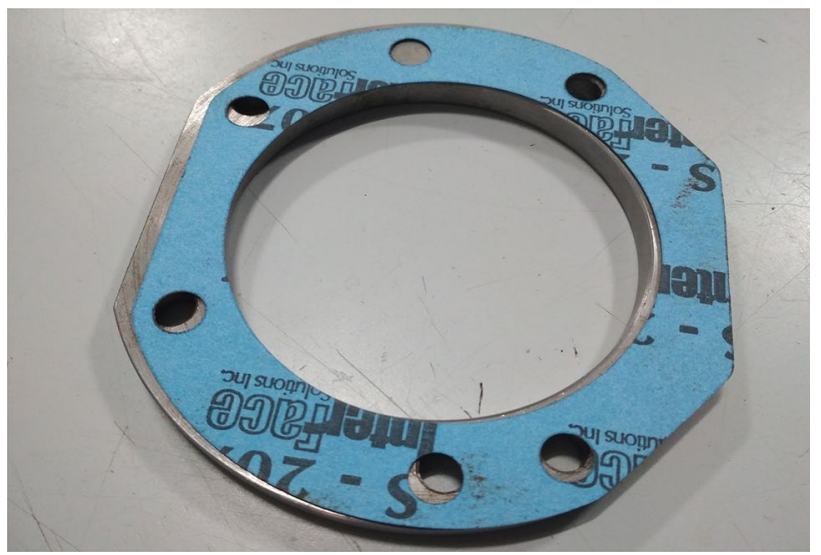

Fig. 8 P501 transaxle gasket

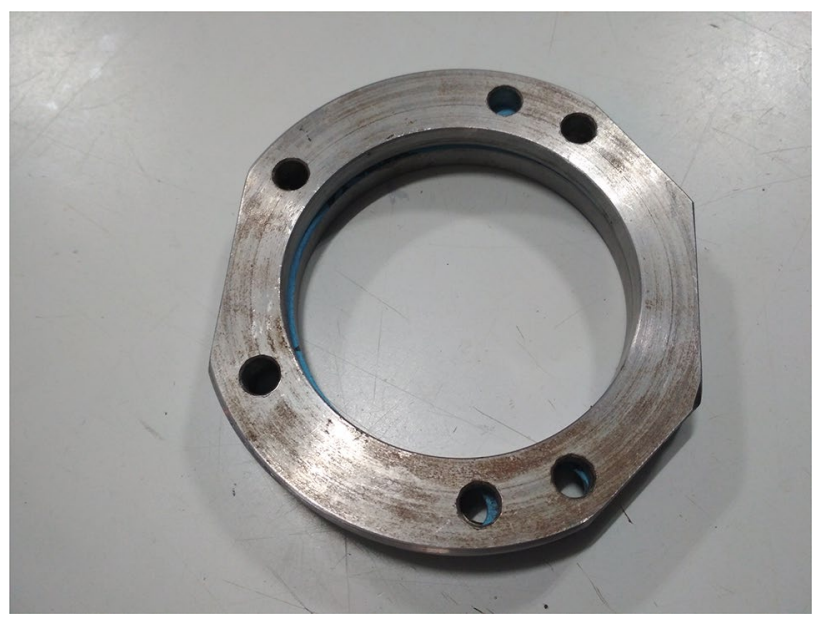

Fig. 9 Gearbox flange and gasket

As shown in Figs. 8 and 9, for experimentation, gasket engine gearbox (P501 transaxle gasket) is used. Afterward, the flange assembly is loaded on UTM STS-248 as shown in Fig. 8. Bolt pretension loading $(13,300 \mathrm{~N}$ of each nut and bolt converted into total compressive load of $79,800 \mathrm{~N}$ ) is applied as a uniformly distributed compressive load to flanges.

\section{Results and discussion}

\subsection{Numerical analysis}

In finite element analysis for the gearbox, flange gasket is discretized into finite number of elements by meshing and then boundary conditions are applied to the system. 
Table 4 Deformation for different gasket thicknesses

\begin{tabular}{ll}
\hline $\begin{array}{l}\text { Gasket thickness } \\
(\mathrm{mm})\end{array}$ & $\begin{array}{l}\text { Defor- } \\
\text { mation } \\
(\mathrm{mm})\end{array}$ \\
\hline 1 & 0.0104 \\
2 & 0.0023 \\
3 & 0.0037 \\
\hline
\end{tabular}

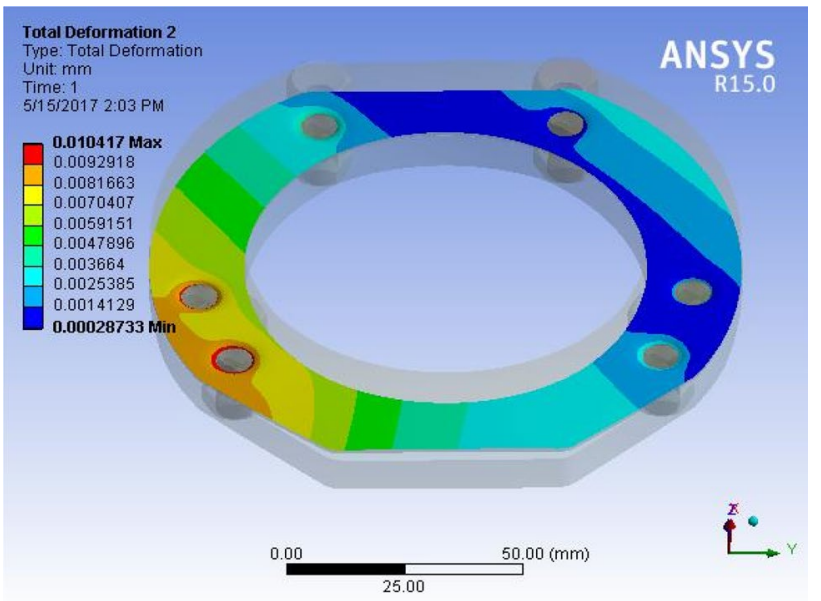

Fig. 10 Deformation for 1-mm gasket

\subsubsection{Deformation plot}

After applying the loading conditions, deformation plot is generated. From Table 4 and Fig. 10, it is seen that the deformations for gasket with $1 \mathrm{~mm}$ thickness were observed as $0.0104 \mathrm{~mm}$, which is substantially higher. Similarly, deformation for gasket with $2 \mathrm{~mm}$ thickness is $0.0023 \mathrm{~mm}$ and with $1 \mathrm{~mm}$ thickness is $0.0037 \mathrm{~mm}$ as shown in Figs. 11 and 12, respectively. Here deformation is higher for 1-mm gasket which can lead to failure of gasket around bolted area. This will lead to leakage and will lose the strength. Here, results also revealed that as the gasket thickness increases deformation starts to reduce.

\subsubsection{Equivalent (von Mises) stress plot}

After applying the loading conditions, equivalent (von Mises) stress plot is generated. From Table 5 and Fig. 13 the equivalent (von Mises) stress for gasket with $1 \mathrm{~mm}$ thickness is observed as $106.99 \mathrm{MPa}$, which is substantially high. Similarly, equivalent (von Mises) stress for gasket with $2 \mathrm{~mm}$ thickness is $79.069 \mathrm{MPa}$ and with $1 \mathrm{~mm}$ thickness is 65.902 MPa as shown in Figs. 14 and 15, respectively. Here von Mises stress is higher for 1-mm gasket which can lead to failure of gasket around bolted area. This will lead to leakage and will lose the strength.

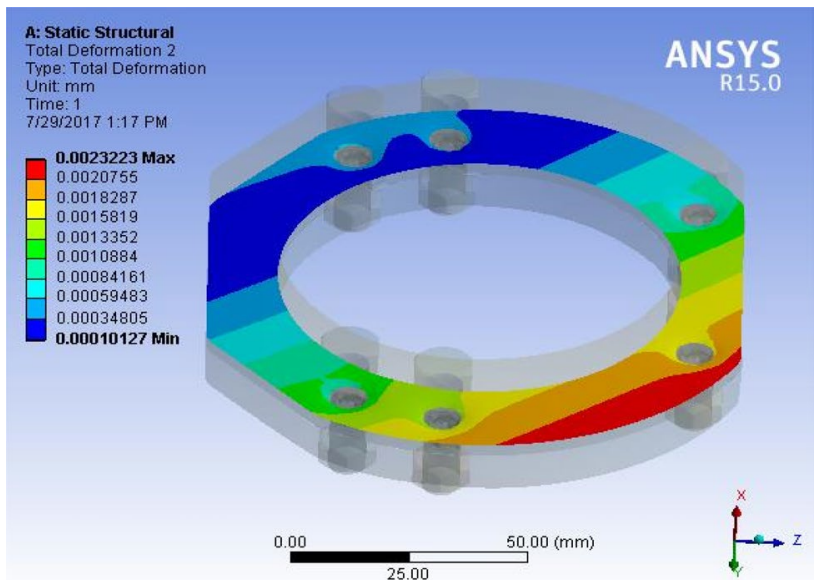

Fig. 11 Deformation for gasket $2 \mathrm{~mm}$

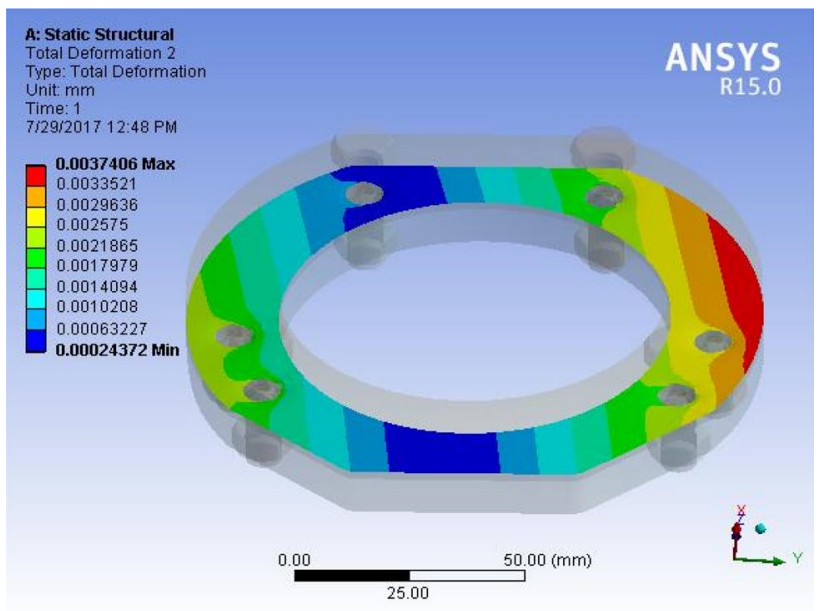

Fig. 12 Deformation for 3-mm gasket

Table 5 Equivalent (von Mises) stress for different gasket thicknesses

\begin{tabular}{ll}
\hline $\begin{array}{l}\text { Gasket } \\
\text { thickness } \\
(\mathrm{mm})\end{array}$ & $\begin{array}{l}\text { Equivalent (von } \\
\text { Mises) stress } \\
(\mathrm{MPa})\end{array}$ \\
\hline 1 & 106.99 \\
2 & 79.069 \\
3 & 65.902 \\
\hline
\end{tabular}

\subsection{Experimental analysis}

\subsubsection{Load versus deformation plot}

Total compressive load of $79,800 \mathrm{~N}$ is applied for gearbox gasket assembly. Load versus deformation plot is generated as shown in Figs. 16, 17 and 18, respectively. 


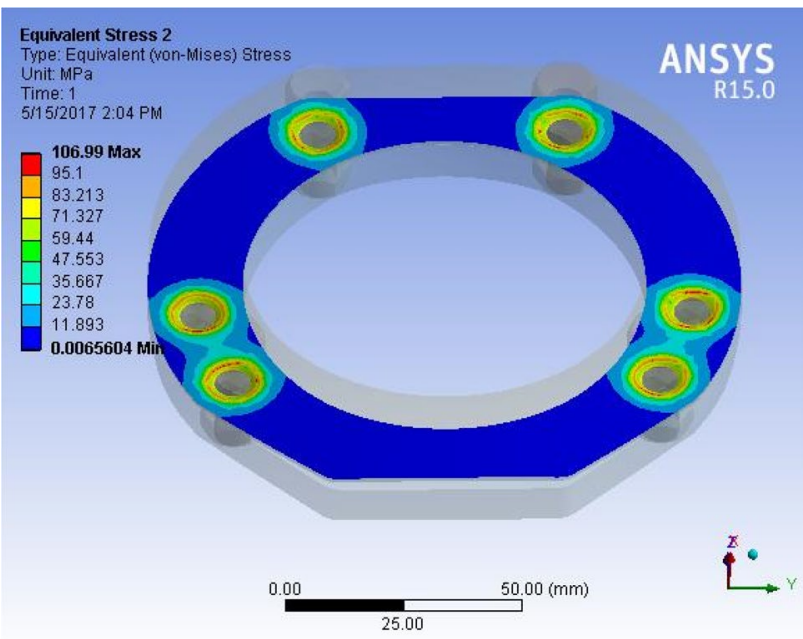

Fig. 13 von Mises stress for 1-mm gasket

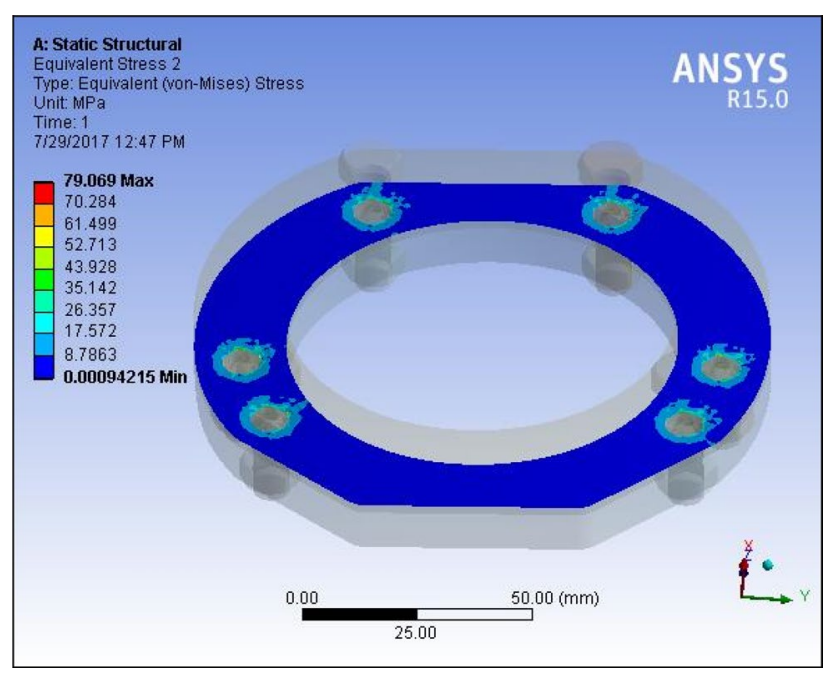

Fig. 14 von Mises stress for gasket $2 \mathrm{~mm}$

Table 6 shows deformation with different gasket thicknesses ranging from 1 to $3 \mathrm{~mm}$. Deformation obtained for gasket with $3 \mathrm{~mm}$ thickness in comparison with a gasket with $1 \mathrm{~mm}$ and $2 \mathrm{~mm}$ thicknesses is significantly reduced from 0.0106 to $0.0041 \mathrm{~mm}$. The percentage error shown in Table 6 is lower. Thus, deformation obtained by numerical approach and experimentation approach appears close.

\section{Conclusion}

The main objective of this research was to study the effect of gasket of different thicknesses on gearbox flange assembly. This objective is achieved with the help of numerical and experimental approach for various thicknesses, viz.

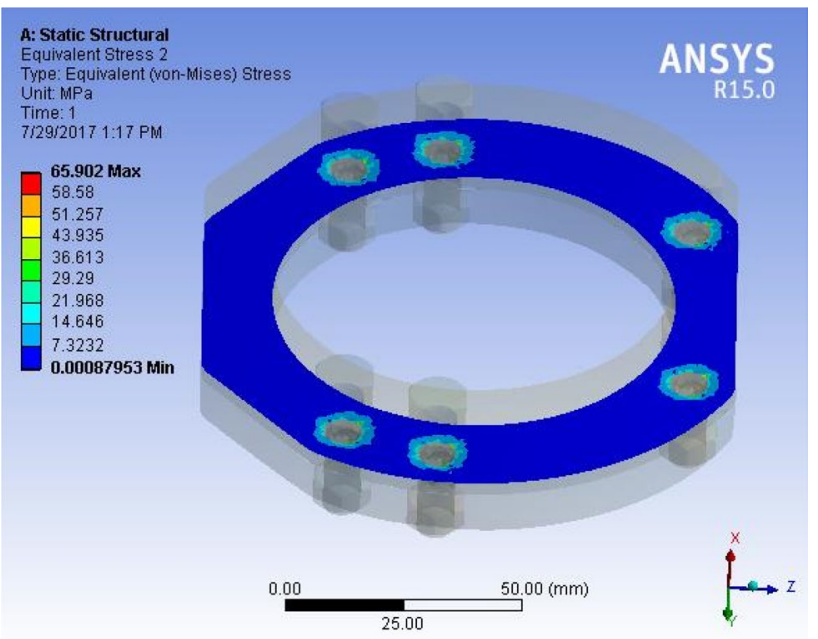

Fig. 15 von Mises stress for 3-mm gasket

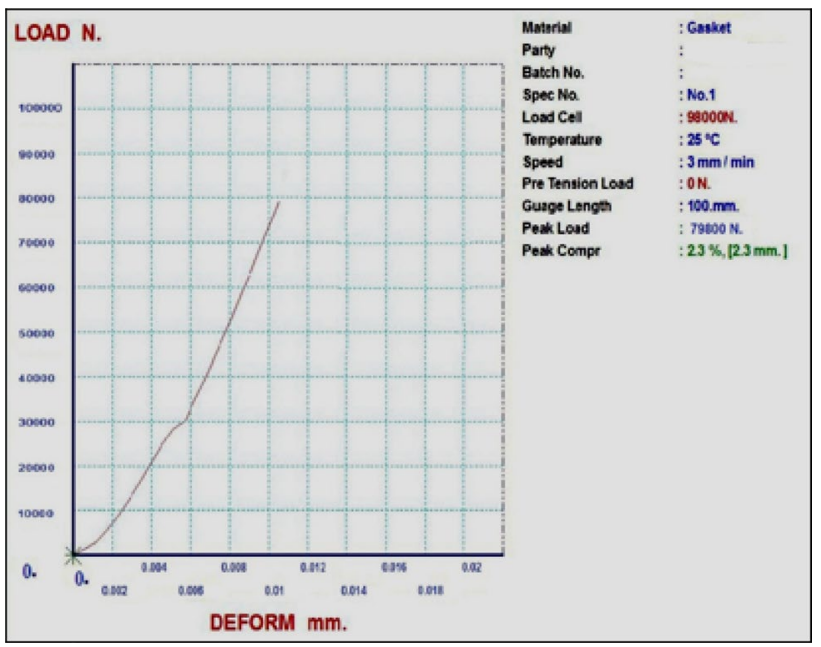

Fig. 16 For 1-mm gasket

$1 \mathrm{~mm}, 2 \mathrm{~mm}$ and $3 \mathrm{~mm}$, respectively. On comparison, it is seen that gasket with $3 \mathrm{~mm}$ thickness shows less deformation with similar trends in von Mises stress. A finite element analysis was performed to investigate the leakage and structural integrity of the gearbox flange assembly for the design conditions for bolt preload. It was also determined that the difference between FEA and experimental values is less than $10 \%$. So, it is concluded that the gasket with $3 \mathrm{~mm}$ thickness is structurally safe to use in the flange and the bolt.

\section{SN Applied Sciences}




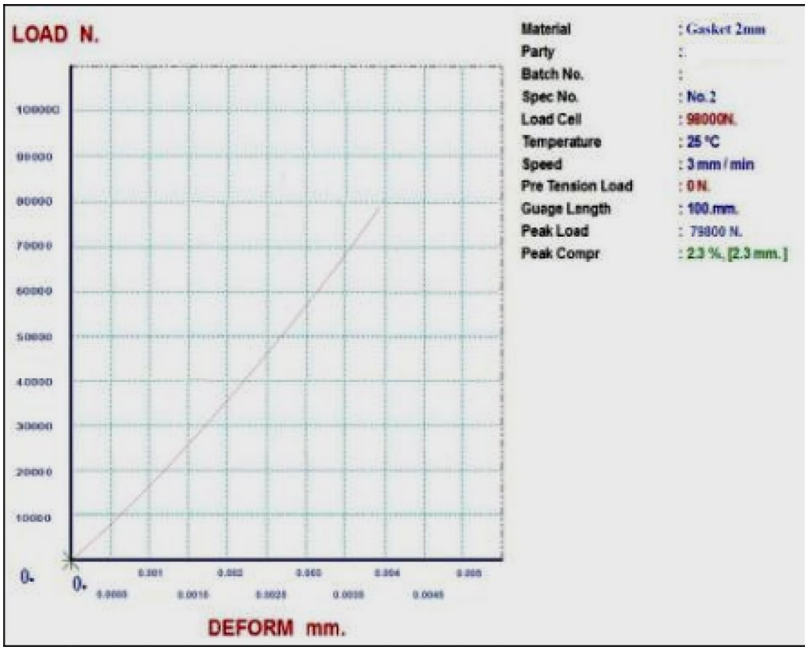

Fig. 17 For gasket $2 \mathrm{~mm}$

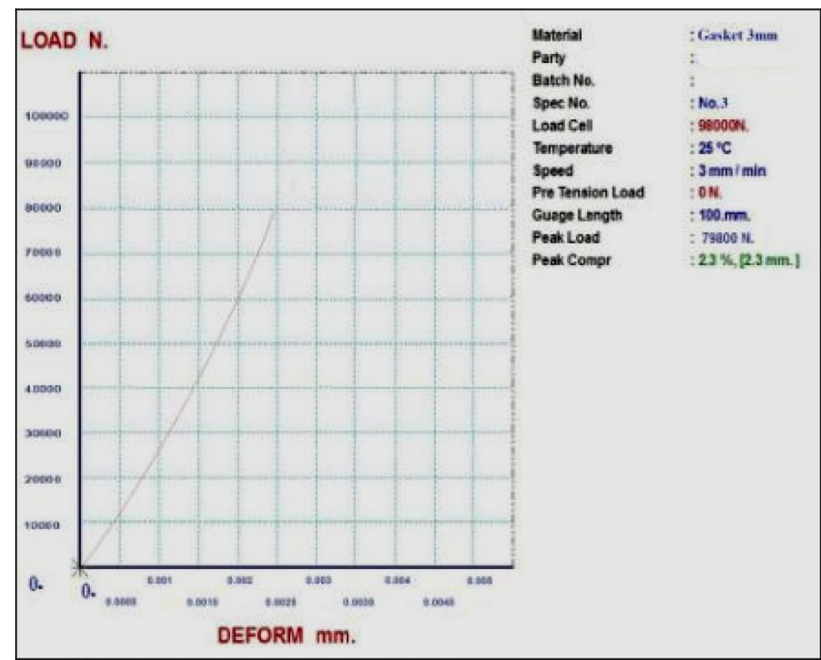

Fig. 18 For 3-mm gasket

\section{Compliance with ethical standards}

Conflict of interest The authors declare that there is no conflict of interests regarding the publication of this paper.

\section{References}

1. Guruchannabasavaiah NG, Shanmugam P, Arun LR (2013) Effect of temperature and associated deformations on the gasket seal compression in a pressure vessel. Int J Sci Eng Res 4(8):74-80

2. Jagale MJ, Surde AN (2016) Analysis of stresses in bolted flange: a review. IOSR J Mech Civ Eng 5:61-64

3. Kaswala B, Hirpara K (2013) A review and case study: bolt pretension. Int J Sci Eng Res 4(8):64-69

4. Omiya Y, Sawa T, Takagi Y (2014) Stress analysis and design of bolted flange connections under internal pressure. In: Pressure vessels and piping conference PVP, vol 2

5. Kapgate KM, Handa CC, Dhopte VD (2015) Conventional design and finite element analysis for bolted joint: a review. Int J Sci Res Dev 3(6):214-218

6. Lee CC, Chiang K, Chen W, Chen R (2005) Design and analysis of gasket sealing of cylinder head under engine operation conditions. Finite Elem Anal Des 41(11-12):1160-1174

7. Kumar DV, Sreenivasulu V, Rao PD, Kiran CU, Kumar YV (2013) Design and analysis of gasket sealing of cylinder head under engine operation conditions. Int J Innov Eng Technol 2(3):282-288

8. Raub J, Cummins, Inc. Modeling diesel engine cylinder head gaskets using the gasket material option of the SOLID185 element

9. Kumar N, Brahamanandam PVG, Papa Rao BV (2011) 3-D finite element analysis of bolted flange joint of pressure vessel. MIT Int J Mech Eng 1(1):35-40

10. Celik H (2012) Non-linear stress analysis for the bolt connections of a chisel using finite element method. The University of Akdniz, Faculty of Agriculture, Department of agricultural Machinery, Antalya

11. Nelson NR, Prasad N (2016) Sealing behaviour of twin gasketed flange joints. Int J Press Vessels Pip 138:45-50

12. Mathan G, Prasad NS (2011) Studies on gasketed flange joints under bending with anisotropic Hill plasticity model for gasket. Int J Press Vessels Pip 88(11-12):495-500

13. Păunescu M (2006) Experimental research regarding gaskets durability. Int J Fatigue 28(9):1081-1086

14. Cheng Y, Zheng XT, Yu JY, Xu JM, Wang CG, Lin W (2015) Tightness assessment of bolted flange connections considering the creep effect of gasket. Proc Eng 130:221-231

15. Kharat AH, Gadewar SP, Gawande SH (2017) Numerical and experimental investigation of structural gasketing approach for gearbox flange. Int Rev Mech Eng 11(7):520-529
Table 6 Summary of deformation result for different gasket thicknesses with percentage error
Type of loading)

Deformation (by numerical) $[\mathrm{mm}]$

Deformation (by experimental) [mm]

Percentage error $\%$

\begin{tabular}{llll}
\hline Flange assembly with gasket with $1 \mathrm{~mm}$ & 0.0104 & 0.0106 & 1.88 \\
Flange assembly with gasket with $2 \mathrm{~mm}$ & 0.0023 & 0.0024 & 4.16 \\
Flange assembly with gasket with $3 \mathrm{~mm}$ & 0.0037 & 0.0041 & 9.75 \\
\hline
\end{tabular}

